\title{
Response of Tapered Piles under Lateral Harmonic Vibrations
}

\author{
Ahmad Dehghanpoor and Mahmoud Ghazavi \\ Department of Civil Engineering, K.N. Toosi University of Technology, Tehran, Iran
}

\begin{abstract}
This paper presents a new method for analysis tapered piles under lateral harmonic vibration. The behavior of tapered piles is assumed to be as elastic and linear. The soil consists of some elastic horizontal layers that they are homogeneous, isotropic, and linearly visco-elastic. The pile is divided to some segments and the differential equation for a given desirable segment is obtained and solved. Then the dynamic complex stiffness parameters are derived for the pile head. Parametric studies have been performed to investigate the influence of pile geometry, soil properties, and loading details on pile-soil system amplitudes. It has been found that under lateral harmonic vibrations, with increasing the pile taper angle, the resonant amplitude decreases. In addition, it has been concluded that under lateral harmonic vibrations, a tapered pile experiences lower amplitude than a cylindrical pile of the same length and material volume.
\end{abstract}

Keywords: Tapered Piles, Lateral Harmonic Vibration, Stiffness, Damping

\section{INTRODUCTION}

There are various methods for studying behavior of dynamically loaded uniform piles. These are continuum approach (Novak, [1]; Novak and Aboul - Ella, [2]; and Nogami, [3]), boundary element method (Kaynia and Kausel, [4]; Sen, Kausel and Banerjee, [5]), lumped-mass method (Penzien, [6]); and finite element solutions (Blaney, Kausel and Rosset, [7]; Wolf and Von Arx, [8]; chow, [9]). Novak presented an approximate continuum approach to account for soil-pile interaction: it is assumed that the soil is composed of a set of independent horizontal layers of infinitesimal thickness, which extend to infinity. As each plane is considered independent, this model may be viewed as a generalized Winkler model. The planes are homogeneous, isotropic, and linearly elastic, and they consider being in a plane strain state. Using Baranov's [10] solution for the horizontal soil reaction to a rigid circular disc with harmonic horizontal displacement (representing a pile cross section), Novak formulated the differential equation of the damped pile in horizontal vibration. He found the steady state (particular) solution for harmonic motion induced through pile ends, and used this solution to find the dynamic stiffness of the pile head for different boundary conditions.

The existent methods are few for analyzing tapered piles under dynamic loads, so recently it has been attracted many investigators. The most studies in this piles, related to vertical harmonic vibrations such as finite difference method (Saha and Ghosh, [11]) and mathematical method (Xie and Vaziri, [12]).

Investigations have been done on tapered piles includes: Full finite element, analytical solution and laboratory tests (Kurian and Moola, [13]), and centrifuge model tests (El Naggar and sakr, [14]). Field load tests were also conducted on tapered piles to investigate their loadcarrying capacity (Rybnikov,) and indicate that bored castin-place tapered piles can have bearing capacity 20-30\% higher than that for cylindrical piles with the same volume and same mean radius. The Ghazavi has also recently performed full-scale tests on a tapered pile driven into a cohesive soil profile in the field. These tests showed that, in long term, the tapered pile had $80 \%$ more capacity than a uniform pile of the same volume and length. Zil'berberg and Sherstnev [15] have reported from their field tests that driven tapered piles in sandy soils can give a stiffer and stronger axial response resulting in a $200-250 \%$ increase in bearing capacity when compared to the capacity of cylindrical piles with the same volume and mean radius. The response of these piles under lateral static loads was also investigated El Naggar and Wei, [16]. El Naggar and Wei [17] also conducted tests in a pressure chamber on tapered model piles subjected to uplift loads.

Ghazavi et al. [18] described the performance of tapered Pile during Pile driving and Ghazavi and Tavassoli [19] Study of Pile geometry on Pile driving. Also has proceeded analysis of kinematic seismic response of tapered piles (Ghazavi, [20]) and Response of tapered piles to axial harmonic loads and effect of angles on tapered piles has been discussed then obtained has been verified whit finite element methods and they were satisfactory (Ghazavi, [21]).

SSM (Segment by Segment Method) is based on continuum method of Novak elasto- dynamic approach for analysis of piles. The SSM has been applied to uniform piles under axial compressive loads (Ghazavi et al. [22]), uplift static loads (Ghazavi et al. [23]), and axial and lateral harmonic vibrations (Ghazavi, [24], Ghazavi and Dehghanpour [25]) in this paper SSM was applied to analyze dynamic behavior of tapered piles under lateral harmonic loads.

\section{ANALYTICAL MODEL}

The characteristic effects of surrounding soil on the pile response are determined with stiffness and damping parameters of soil - pile system. These effects can be taken in to account if a proper soil reaction is employed. For analyzing tapered pile, it was idealized to some cylindrical segments with different diameter that connected together by rigidly at nodes. This idealization was used in tapered piles under harmonic axial vibration [11-12] and [21]. 
Surrounding soil reaction to the loaded tapered pile segments had been presented by $\mathrm{V}_{\mathrm{s}}(\mathrm{z}, \mathrm{t})$ and $\mathrm{V}_{\mathrm{r}}(\mathrm{z}, \mathrm{t})$, that shear resistance per unit length of the pile shaft and horizontal reaction at the horizontal annular projections of the pile shaft, respectively. Parameters $\mathrm{z}$ and $\mathrm{t}$ represent depth and time in order as shown in Fig 1.

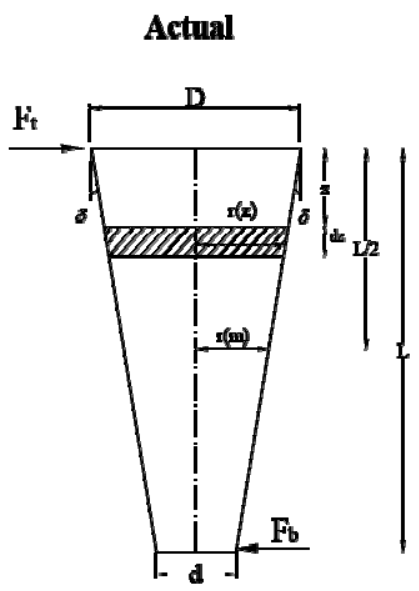

(a)

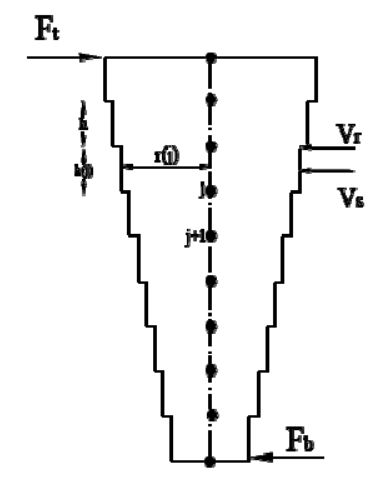

(b)
Fig.1 Idealization of tapered pile for dynamic analysis in laterally inhomogeneous media using segment by segment, (a) Actual pile; (b) Idealized pile

The soil response with time to motion of the pile toe, $F_{b}(t)$, is taken as that of a viscoelastic half - space to rigid, mass less, circular disc of radius $\mathrm{r}_{\mathrm{b}}$ undergoing harmonic vibration. This can be expressed as:

$$
F_{b}(t)=G_{b} r_{b}\left[C_{u_{1}}\left(a_{o b}, v, D\right)+i C_{u 2}\left(a_{o b}, v, D\right)\right] u_{b}(t)
$$

Where $G_{b}$ is the soil shear modulus at the pile toe, $C_{u l}, C_{u 2}$ are dimensionless complex parameters given in the form of polynomial expressions (Veletsos and Vbric, [26]), $\mathrm{u}_{\mathrm{b}}(\mathrm{t})$ is the toe horizontal displacement, $\mathrm{r}_{\mathrm{b}}$ is pile radius at the pile tip, $a_{o b}=\frac{r_{b} \omega}{V_{b}}$, where $\mathrm{V}_{\mathrm{b}}$ is shear wave Velocity of soil below the tip, $\omega$ is circular frequency, $v$ is Poisson's ratio, D is material damping.

The soil reaction on the pile is represented by springs and dashpots, which are modeled on elasto - dynamic theory. The interaction of the soil and the pile is then determined for each segment according to the characteristics of soil. This interaction can be demonstrated by a complex displacement, shear force, rotation and bending moment at the end of the adjacent segment. This procedure is performed from the lowest pile segment and extends to the next upper segment. This manner is continued to reach the topmost segment. That is why this procedure is called the SSM (Ghazavi [18-25]).

In the analysis, it is assumed that the soil reaction associated with a given soil layer is identical to that of an infinite rigid pile undergoing a uniform displacement of the same properties as the soil of that layer. This assumption is essential to the solution and will be examined subsequently using other, existing solutions. This assumption has also been used by other researcher [2]. In one dimensional finite element analysis of cylindrical piles under torsional vibrations, Novak and Howell also used the same assumption. A somewhat similar assumption was also made and by Mylonakis and Gazetas [30] for axially loaded cylindrical piles in a layered soil profile. It is note that Novak and Aboul - Ella used finite element method (FE) for analysis of piles embedded in inhomogeneous soil and subject to lateral harmonic vibrations. By considering the typical embedded segment $\mathrm{j}$ at depths, shown in Fig 1 and on the basis of the above assumption, the following governing dynamic differential equation of a soil - pile system subjected to harmonic lateral load can be obtained [1]:

$m_{\dot{p} j} \frac{\partial^{2} u_{j}(z, t)}{\partial t^{2}}+C_{\dot{p} j} \frac{\partial^{2} u_{j}(z, t)}{\partial t}+E_{\dot{p} j} I_{\dot{p} j} \frac{\partial^{4} u_{j}(z, t)}{\partial z^{4}}+G_{s j} S_{u j} u_{j}(z, t)=0$

Where $\mathrm{m}_{\mathrm{pj}}$ the pile mass per unit length, $\mathrm{C}_{\mathrm{pj}}$ is the damping coefficient of the pile material, $E_{p j} I_{p j}$ is the bending stiffness of the pile segment $j, G_{s j}$ is the shear modulus of the soil layer surrounding the pile segment $\mathrm{j}, \mathrm{u}_{\mathrm{j}}(\mathrm{z}, \mathrm{t})$ is the local time - dependent complex amplitude at depth $\mathrm{z}$ from the top of segment $\mathrm{j}$ and $\mathrm{S}_{\mathrm{uj}}$ is Complex dimensionless soil resistance parameter defined elsewhere [1] as a function of Poisson's ratio and dimensionless frequency, $a_{\circ j}=r_{o j} \omega / V_{s j} \quad$ Here $r_{0 j}$ is the pile segment radius, $\omega$ is the circular frequency, and $V_{s j}$ the shear Wave velocity of the soil surrounding the pile segment $\mathrm{j}$. The four terms in (2) represent the inertia force due to lumped mass of the pile, the damping force of pile material, the lateral interaction between pile segments, and the soil resistance, respectively. For harmonic vibration, the local displacement $\mathrm{u}_{\mathrm{j}}(\mathrm{z}, \mathrm{t})$ is given by:

$u_{j}(z, t)=u_{j}(z)_{e}^{i \omega t}$

Where $u_{j}(z)$ is the complex amplitude at depth $z$ from the top of segment $\mathrm{j}$ and $\omega$ is the excitation frequency:

$$
u_{j}(z)=u_{1 j}(z)+i u_{2 j}(z)
$$

Combining (2) and (3) gives

$$
E_{p j} I_{p j} \frac{\partial^{4} u_{j}(z)}{\partial z^{4}}+u_{j}(z)\left[G_{s j} S_{u 1}-m_{p j} \omega^{2}+i\left(C_{p j} \omega+G_{s j} S_{u 2}\right)\right]=0
$$

The above equation can be solved explicitly. The solution for the displacement at a point at vertical distance $\mathrm{z}$ below the upper node of segment $\mathrm{j}$ is given by:

$u_{j}(z)=A_{j} \operatorname{Cosh}\left(\zeta_{j} \frac{z}{h_{j}}\right)+B_{j} \sinh \left(\zeta_{j} \frac{z}{h_{j}}\right)+C_{j} \cos \left(\zeta_{j} \frac{z}{h_{j}}\right)+D_{j} \sin \left(\zeta_{j} \frac{z}{h_{j}}\right)$

(6)

Where

$\zeta_{j}=h_{j} \sqrt[4]{\frac{1}{E_{p j} I_{P j}}\left[m_{p j} \omega^{2}-G_{s i} S_{u q}-i\left(C_{p j} \omega+G_{s j} S_{u 2}\right)\right]}$

Where $A_{j}, B_{j}, C_{j}$ and $D_{j}$ are integration constants determined using appropriate boundary conditions. 
If the displacement, rotation, shear force and bending moment transmitted by the pile at node 2 of segment $\mathrm{j}$ are know, the integration constants $A_{j}, B_{j}, C_{j}$ and $D_{j}$ can be calculated. Thus, the displacement, rotation, bending moment and shear force at node 1 of segment $\mathrm{j}$ are respectively given by (8a-8d).

\section{PARAMETRIC STUDIES FOR PILE GEOMETRY}

\section{EFFECT}

In this section, four type of piles whit difference geometry under lateral harmonic load and have same length and volume had been studied and the results are compared. Properties of tapered piles and soil have presented in Table 1. All piles are $10 \mathrm{~m}$ of length and there volumes are 1.36 $\mathrm{m}^{3}$. Pile C is cylindrical. Pile T-C consists of a top tapered segment with $5 \mathrm{~m}$ length and a lower cylindrical segment with $5 \mathrm{~m}$ length. Pile C-T has top cylindrical part with $5 \mathrm{~m}$ followed by a tapered part with $5 \mathrm{~m}$ length. Pile $\mathrm{T}$ is tapered. Taper angles of piles are $0.5^{\circ}$ and $1.5^{\circ}$ that has been shown in Fig 2 and Table 2.
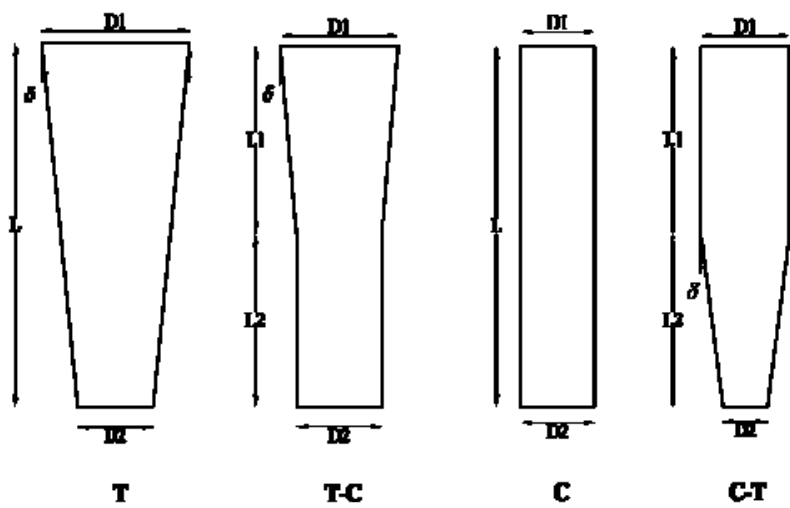

Fig. 2 Pile configurations

Table 2 Dimension of tapered piles for Fig 3. $u_{j 1}=\frac{V_{j 2} h_{j}^{3}\left(\sinh \xi_{j}-\sin \xi_{j}\right)+\xi_{j}^{2} E_{p_{j}} I_{p_{j}} \theta_{j 2} h_{j}\left(\sinh \xi_{j}+\sin \xi_{j}\right)+\xi_{j}^{3} E_{p_{j}} I_{p_{j}} u_{j 2}\left(\cosh \xi_{j}+\cos \xi_{j}\right)+M_{j 2} h_{j}^{2} \xi_{j}\left(\cos \xi_{j}-\cosh \xi_{j}\right)}{2 E_{p_{j}} I_{p} \xi_{j}^{3}}$

$\theta_{j 1}=\frac{V_{j 2} h_{j}^{3}\left(\cos \xi_{j}-\cosh \xi_{j}\right)-\xi_{j}^{2} E_{p_{j}} I_{p_{j}} \theta_{j 2} h_{j}\left(\cosh \xi_{j}+\cos \xi_{j}\right)+\xi_{j}^{3} E_{p_{j}} I_{p_{j}} u_{j 2}\left(\sin \xi_{j}-\sinh \xi_{j}\right)+M_{j 2} h_{j}^{2} \xi_{j}\left(\sinh \xi_{j}+\sin \xi_{j}\right)}{2 E_{p_{j}} I_{p} \xi_{j}^{2} h_{j}}$ $M_{j 1}=\frac{V_{j 2} h_{j}^{3}\left(\sinh \xi_{j}+\sin \xi_{j}\right)+\xi_{j}^{2} E_{p_{j}} I_{p_{j}} \theta_{j 2} h_{j}\left(\sinh \xi_{j}-\sin \xi_{j}\right)+\xi_{j}^{3} E_{p_{j}} I_{p_{j}} u_{j 2}\left(\cosh \xi_{j}-\cos \xi_{j}\right)-M_{j 2} h_{j}^{2} \xi_{j}\left(\cosh \xi_{j}+\cos \xi_{j}\right)}{-2 \xi_{j} h_{j}^{2}}$

$V_{j 1}=\frac{-V_{j 2} h_{j}^{3}\left(\cosh \xi_{j}+\cos \xi_{j}\right)-\xi_{j}^{2} E_{p_{j}} I_{p_{j}} \theta_{j 2} h_{j}\left(\cosh \xi_{j}-\cos \xi_{j}\right)-\xi_{j}^{3} E_{p} I_{p} u_{j 2}\left(\sinh \xi_{j}+\sin \xi_{j}\right)+M_{j 2} h_{j}^{2} \xi_{j}\left(\sinh \xi_{j}-\sin \xi_{j}\right)}{-2 h_{j}^{3}}$

(8a)- (8d)

Table1. Properties of tapered piles and soil

\begin{tabular}{|c|c|}
\hline Radius of equivalent circular pile, & $0.208 \mathrm{~m}$ \\
$\mathrm{r}_{\mathrm{eq}}{ }^{*}$ & \\
\hline Shear wave velocity in soil, $\mathrm{V}_{\mathrm{s}}$ & $84 \mathrm{~m} / \mathrm{s}$ \\
\hline Soil Poisson's ratio, $v_{\mathrm{s}}$ & 0.45 \\
\hline Soil unit weight, $\gamma_{\mathrm{s}}$ & $17.5 \mathrm{kN} / \mathrm{m}^{3}$ \\
\hline Pile modulus of elasticity, $E_{p}$ & $1.962 \times 10^{7}$ \\
& $\mathrm{kN} / \mathrm{m}^{2}$ \\
\hline Soil modulus of elasticity, $E_{s}$ & $3.58 \times 10^{4}$ \\
& $\mathrm{kN} / \mathrm{m}^{2}$ \\
\hline Pile unit weight, $\gamma_{\mathrm{p}}$ & $25 \mathrm{kN} / \mathrm{m}^{3}$ \\
\hline
\end{tabular}

${ }^{*} \mathrm{r}_{\mathrm{eq}}$ is radius of cylindrical pile of the same volume and length as tapered pile)

\begin{tabular}{|c|c|c|c|c|c|c|c|c|}
\hline Piles & $\begin{array}{c}\text { Taper } \\
\text { Angl } \\
\mathrm{e}\end{array}$ & \multicolumn{9}{|c|}{$\delta=0.5^{\circ}$} & \multicolumn{4}{c|}{$\delta=1.5^{\circ}$} \\
\hline $\mathrm{T}$ & $\mathrm{L}=10 \mathrm{~m}$ & $\mathrm{D}_{1}=0.5 \mathrm{~m}$ & $\mathrm{D}_{2}=0.326 \mathrm{~m}$ & $\mathrm{~L}=10 \mathrm{~m}$ & $\mathrm{D}_{1}=0.65 \mathrm{~m}$ & $\mathrm{D}_{2}=0.126 \mathrm{~m}$ \\
\hline $\mathrm{C}$ & $\mathrm{L}=10 \mathrm{~m}$ & $\mathrm{D}_{1}=0.416 \mathrm{~m}$ & $\mathrm{D}_{2}=0.416 \mathrm{~m}$ & $\mathrm{~L}=10 \mathrm{~m}$ & $\begin{array}{c}\mathrm{D}_{1}=0.416 \\
\mathrm{~m}\end{array}$ & $\mathrm{D}_{2}=0.416 \mathrm{~m}$ \\
\hline $\mathrm{TC}$ & $\begin{array}{c}\mathrm{L}_{1}=5 \\
\mathrm{~m}\end{array}$ & $\begin{array}{c}\mathrm{L}_{2}=5 \\
\mathrm{~m}\end{array}$ & $\mathrm{D}_{1}=0.48 \mathrm{~m}$ & $\begin{array}{c}\mathrm{D}_{2}=0.393 \\
\mathrm{~m}\end{array}$ & $\begin{array}{c}\mathrm{L}_{1}=5 \\
\mathrm{~m}\end{array}$ & $\begin{array}{c}\mathrm{L}_{2}=5 \\
\mathrm{~m}\end{array}$ & $\begin{array}{c}\mathrm{D}_{1}=0.603 \\
\mathrm{~m}\end{array}$ & $\begin{array}{c}\mathrm{D}_{2}=0.342 \\
\mathrm{~m}\end{array}$ \\
\hline $\mathrm{CT}$ & $\begin{array}{c}\mathrm{L}_{1}=5 \\
\mathrm{~m}\end{array}$ & $\begin{array}{c}\mathrm{L}_{2}=5 \\
\mathrm{~m}\end{array}$ & $\begin{array}{c}\mathrm{D}_{1}=0.4369 \\
\mathrm{~m}\end{array}$ & $\begin{array}{c}\mathrm{D}_{2}=0.3497 \\
\mathrm{~m}\end{array}$ & $\begin{array}{c}\mathrm{L}_{1}=5 \\
\mathrm{~m}\end{array}$ & $\begin{array}{c}\mathrm{L}_{2}=5 \\
\mathrm{~m}\end{array}$ & $\begin{array}{c}\mathrm{D}_{1}=0.4729 \\
\mathrm{~m}\end{array}$ & $\begin{array}{c}\mathrm{D}_{2}=0.2111 \\
\mathrm{~m}\end{array}$ \\
\hline
\end{tabular}


SSM was applied with assumption pinned-ended for all of above piles and Fig. 2 illustrate the dimensionless amplitude lateral versus the excitation frequency for piles with taper angles $\delta=0.5^{\circ}$ that results have been shown in Fig. 3 the $\mathrm{T}$ pile have the least lateral and rotary response amplitude and after $\mathrm{T}$ Pile. There are $\mathrm{T}-\mathrm{C}, \mathrm{C}-\mathrm{T}$ and $\mathrm{C}$ respectively.

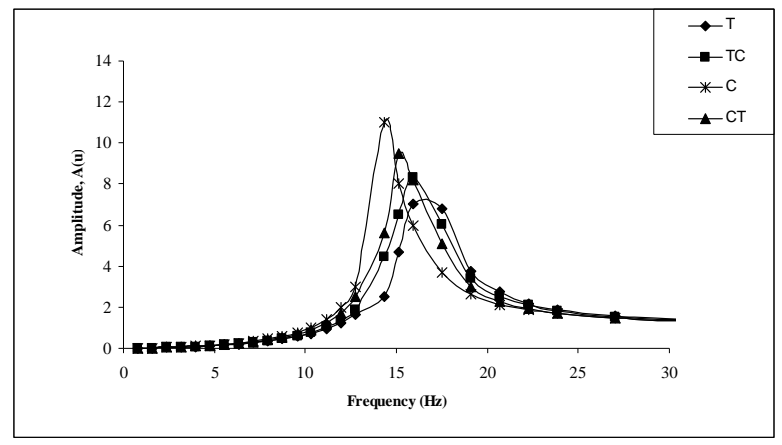

Fig. 3 Variation of lateral dimensionless amplitude versus

$$
\text { frequency for } \mathrm{T} \text { pile }\left(\delta=0.5^{\circ}\right)
$$

It is noted that in the $\mathrm{C}$ piles, the resulted values of are exactly the same as those reported by Novak [1].

In Fig. 4, the dimensionless amplitude lateral versus the excitation frequency had been compared based on taper angle in $\mathrm{T}$ pile and observed with increasing taper pile, dimensionless response amplitudes will decrease.

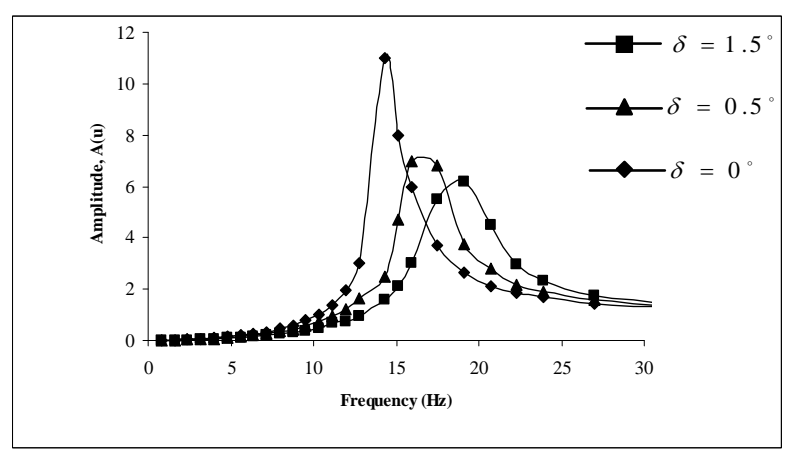

Fig. 4. Comparison variation of lateral dimensionless amplitude versus frequency for $\mathrm{T}$ pile according to taper angle

\section{CONCLUSION}

A simple approach, called SSM, has been presented in this paper for determination of stiffness and damping parameters of laterally loaded tapered piles subjected to harmonic vibrations. The soil-pile interaction in this method is modeled within each segment and applied via the segment nodes to the analysis of the adjacent segment. Therefore, the stiffness and damping parameters for the whole pile-soil system are determined. According to results SSM, T, TC,
CT and C piles respectively have the least lateral and rotary response amplitude and observed that for tapered piles of the same volume and length under lateral harmonic vibrations, with increasing the taper angle, the resonant frequency increases slightly. However, the reduction of the amplitude is more pronounced.

The SSM is an efficient and simple method for analysis of tapered piles under harmonic vibration. In particular, the effects of the soil in homogeneity in the vertical direction even with complicated stratifications can be easily captured. This method involves less computational work than available numerical method based on the FE.

\section{REFERENCES}

[1] Novak M, “Dynamic stiffness and damping of piles”, Canadian Geotechnical Journal, Vol. 11, No. 4, 1978, 574-598.

[2] Novak M, and Aboul-Ella F, "Impedance functions of piles in layered media", Journal of Geotechnical Engineering Division ASCE, Vol. 104, No. 6, 1978, 643-661.

[3]Novak M, and Nogami T, "Coefficients of soil reaction to pile vibration”, Journal of Geotechnical Engineering Division ASCE, Vol. 106, No. 5, 1980, 565-570.

[4] Kaynia A.M, and Kausel E, "Dynamic behavior of pile groups”, Proceedings 2nd International Conference on Numerical Methods in Offshore Piling, Austin, Texas, 1982,509-532.

[5] Sen R, and Kausel E, and Banerjee, P.K., "Dynamic analysis of pile groups embedded in non-homogeneous soils" International Journal for Numerical and Analytical Methods in Geomechanics, Vol. 9, No. 6, 1985, 507-524.

[6] Penzien J, “Soil-pile interaction”. Earthquake Engineering, R.L. Wiegel, ed., Prentice Hall Inc., Englewood Cliffs, N.J. 349-381.

[7] Blaney G.W, Kausel, E, and Roesset J.M, "Dynamic stiffness of piles", Proceedings 2nd International Conference on Numerical Methods in Geomechanics, Blacksburg,Virginia,1976,1001-1012.

[8] Wolf J.P, and von Arx G.A, “Horizontally travelling waves in a group of piles taking pile-soil-pile interaction into account”, International Journal of Earthquake Engineering and Structural Dynamics, 1982, Vol. 10, 225-237.

[9] Chow Y.K, "Dynamic response of axially loaded piled foundations”, Proceedings 5th International Conference on Numerical Methods in Geomechanics, Nagoya, Japan, 1985,1485-1492.

[10] Baranov V.A, "On the calculation of an embedded foundation”, (in Russian), Voprosy Dinamiki Prochnosti, Polytechnical Institute of Riga, 1967, No. 14, 195-209.

[11] Saha S, and Ghosh D.P, "Vertical vibration of tapered piles”, Journal of Geotechnical Engineering, ASCE, 1986, vol.112,No.3,290-301.

[12] Xie J, and Vaziri H.H, "Vertical vibration of nonuniform piles”, Journal of Geotechnical Engineering ASCE, 1991, Vol.117,No.5,1105-1118. 
[13] Kurian N.P, and Srivinas M.S, "Studies on the behavior of axially loaded tapered piles by the finite element method", International Journal of Numerical and Analytical Methods in Geomechanics, 1995, Vol. 19, 869-888.

[14] El Naggar H, and Sakr M, "Evaluation of axial performance of tapered piles from centrifuge tests", Canadian Geotechnical Journal, 2000, Vol, 37, 1295-1308.

[15] Zil'berberg S. D, and Sherstnev A. D, “Construction of compaction tapered pile foundations (from the experience of the "Valdespetsstroi" Trust)", Soil Mechanic and Foundation Engineering, 1990, 27(3), 96-101.

16] El Naggar H, and Wei J.Q, "Response of tapered piles subjected to lateral loading”, Canadian Geotechnical Journal,1999,Vol,36,52-71.

[17] El Naggar H, and Wei J.Q, "Experimental study of axial behaviour of tapered piles”, Canadian Geotechnical Journal,1998,Vol,35,641-654.

[18] Ghazavi M, Williams D. J., and Wong K.Y, “Analysis of a tapered pile during pile driving”, Proceedings $2^{\text {nd }}$ International Conference on Multi - Purpose High-Rise Towers and Tall Buildings, Singapore, 1996, 87-94.

[19] Ghazavi M, and Tavassoli O., "Numerical Analysis for Pile Geometry Effect on Drivability”. Proceedings of the $8^{\text {th }}$ International Conference on the Application of Stress Wave Theory to Piles, Lisbon, Portugal, 2008, pp. 271- 276.

[20] Ghazavi M., “Analysis of Kinematic Seismic Response of Tapered Piles". Geotechnical and Geological Engineering, an International Journal, 2007, vol. 25, No. 1, 37-44.

[21] Ghazavi M., "Response of Tapered Piles to Axial Harmonic Loading”., Canadian Geotechnical Journal, 2008, 45(11):1622-1628.
[22] Ghazavi M., Williams D. J., and Morris P.H, “Analysis of axially loaded piles embedded in layered deposits”, Proceedings 2nd International Conference on the Application of Numerical Methods in Engineering, Universiti Pertanian Malaysia, Selangor, 1997a, Malaysia, 335-344.

[23] Ghazavi M., Wiiliams D.J., and Morris P.H, “Analysis of piles subjected to uplift loads”, Proceedings 2nd International Symposium on Structures and Foundations in Civil Engineering, Hong Kong, 1997b, 177-183.

[24] Ghazavi M. "Vertical vibration of deep foundations in layered deposits", Proceedings of Iranian Third International Seminar on Soil Mechanics and Geotechnical Engineering (ISSMGE), 2002, Tehran, Iran, Vol. I, 223-228.

[25] Ghazavi M., Dehghanpour A, "Dynamic Analysis of Piles under Lateral Harmonic Vibration”. Fifth International Conference on Recent Advances in Geotechnical Earthquake Engineering and Soil Dynamics, May 24-29, 2010; San Diego, California, USA. [26]Veletsos A.S., and Verbic B., "Vibration of Viscoelastic Foundations. Earthquake Engineering and Structural Dynamics”, 1973, Vol 2, No. 1, 87-102.

International Journal of GEOMATE, June, 2012, Vol. 2, No. 2 (Sl. No. 4), pp. 261-265

MS No.4c received August 31, 2011, and reviewed under GEOMATE publication policies.

Copyright (C) 2012, International Journal of GEOMATE. All rights reserved, including the making of copies unless permission is obtained from the copyright proprietors. Pertinent discussion including authors' closure, if any, will be published in the June 2013 if the discussion is received by Dec. 2012.

Corresponding Author: Ahmad Dehghanpoor 